\title{
PALM-BASED VITAMIN E (tocotrienol-rich fraction) HAS EXCELLENT STABILITY IN CHEWABLE TABLET AFTER ONE-YEAR OF STORAGE AT AMBIENT TEMPERATURE
}

\author{
NOOR LIDA HABI MAT DIAN*; WAN SUET YING**; FU JU YEN*; PUVANESWARI MEGANATHAN*; NIK \\ MOHD AZNIZAN NIK IBRAHIM*; NORAZURA AILA MOHD HASSIM*; HELMI WASOH** and LAI OI MING;
}

\begin{abstract}
Palm oil is a good source of micronutrients (sometimes called phytonutrients as they are plant-based). The micronutrients constitute about $1 \%$ of crude palm oil. Vitamin $E$ is the most abundant micronutrient of palm oil. Other prevalent micronutrients found in palm oil are carotenes, phytosterols, squalene, coenzyme $Q_{10}$ (ubiquinone), phospholipids (lecithin) and polyphenols. Palm-based vitamin E, also known as tocotrienol-rich fraction (TRF) has been used as a dietary supplement in the form of soft gel capsules, but there is relatively little information about its contribution when processed into a chewable tablet. Stability of the micronutrient during storage is a critical factor to be considered. Based on the general instability of vitamins, endogenous and added vitamins can suffer substantial losses during storage prior to consumption. The retention of vitamin $E$ in the palm-based TRF chewable tablet after one-year storage at ambient temperature was $92.6 \%$. The excellent retention of vitamin $E$ in the chewable tablet was most plausible due to the use of powdered (microencapsulated) palm-based TRF which managed to protect the bioactive component from direct exposure to chemical and physical reactions, thus protecting the bioactive ingredient from degradation. This study indicates that powdered palm-based TRF has good stability during storage and it can be effectively delivered via a chewable tablet form to consumers.
\end{abstract}

Keywords: palm-based tocotrienol-rich fraction (TRF), palm-based vitamin E, palm-based vitamin E stability in chewable tablet, chewable tablet.

Date received: 12 September 2018; Sent for revision: 12 September 2018; Received in final form: 27 November 2018; Accepted: 13 January 2019.

\section{INTRODUCTION}

Vitamin E or tocochromanols is an essential nutrient for the body. Vitamin E comprises four tocopherol and four tocotrienol isomers, namely alpha $(\alpha)$, beta $(\beta)$, gamma $(\gamma)$ and delta $(\delta)$ (Brigelius-Flohé and Traber, 1999). Tocotrienol is distinguishable

\footnotetext{
Malaysian Palm Oil Board, 6 Persiaran Institusi, Bandar Baru Bangi, 43000 Kajang, Selangor, Malaysia. E-mail: nlida@mpob.gov.my

** Department of Bioprocess Technology, Faculty of Biotechnology and Biomolecular Sciences, Universiti Putra Malaysia, 43400 UPM Serdang, Selangor, Malaysia.

‡ Institute of Bioscience, Universiti Putra Malaysia, 43400 UPM Serdang, Selangor, Malaysia.
}

from tocopherol by the degree of saturation at the molecule's side chains. Tocotrienol molecules possess unsaturated geranylgeranyl side chains with three double bonds at carbons 3, 7 and 11, whereas tocopherol molecules possess fully saturated phytyl side chains. The chemical structures of tocopherol and tocotrienol, indicating specific substituents for $\alpha, \beta, \gamma$ and $\delta$ isomers, are shown in Figure 1 .

Palm oil (PO) is one of the richest sources of vitamin E (800-1200 ppm) (Kushairi et al., 2018). Palm-based vitamin E comprises of about 49\%53\% $\gamma$-tocotrienols, 22\%-34\% $\alpha$-tocotrienols, 6\%7\% $\delta$-tocotrienols, $14 \%-17 \% \alpha$-tocopherols and 3\% $\alpha$-tocomonoenol (Puah et al., 2007). As it is very rich in tocotrienols, palm-based vitamin $\mathrm{E}$ is also 


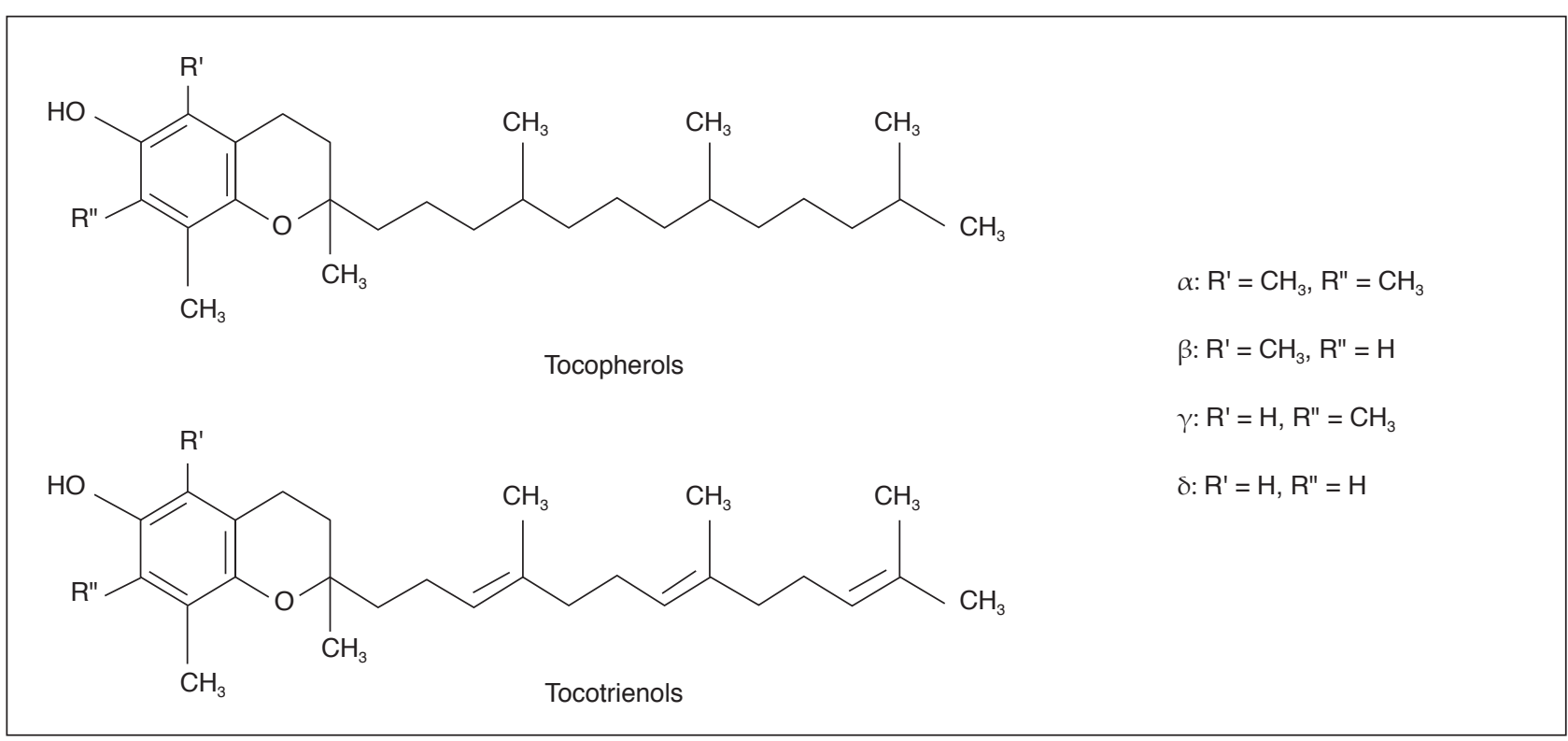

Figure 1. Chemical structures of tocopherols and tocotrienols, indicating specific substituents for $\alpha, \beta, \gamma$ and $\delta$ isomers.

known as tocotrienol-rich fraction (TRF). Palmbased TRF possesses unique and potent healthenhancing properties such as antioxidant (Cerecetto and López, 2007), cardioprotective (Heng et al., 2013), neuroprotective (Sen et al., 2000), anti-cancer and cancer suppression (Wong and Radhakrishnan, 2012) as well as neurological and brain development (Traber, 2014) effects. Palm-based TRF also lowers blood cholesterol levels (Qureshi et al., 1995).

The recommended dietary allowance (RDA) for vitamin $\mathrm{E}$ to maintain good health is about 15 mg per day (or 22.4 IU) for people over the age of 14 years, and $20 \mathrm{mg}$ per day for lactating women (Traber, 2014). The more common dosages fall within the range of 50-360 $\mathrm{mg}$ per day (Tan et al., 1991). The upper limit for safety is $1000 \mathrm{mg}$ per day. A proper lifelong intake of vitamin $\mathrm{E}$ is important for maintaining good health. Adequate levels of this essential micronutrient are especially critical for infants, the elderly and women who are or may become pregnant. Vitamin E deficiency can cause poor transmission of nerve impulses, muscle weakness and degeneration of the retina that leads to blindness. Severe vitamin E deficiency can be lethal, causing loss of life (Traber, 2014).

Oral tablet has been manufactured for more than 150 years. It is the compressed solid form containing a quantified amount or dosage of active ingredients to deliver certain therapeutic effects. In particular, the tablet is usually designed for ease of administration. Nowadays, the oral tablet has evolved into different forms and types to suit the needs of consumers. Four main forms of the oral tablet, namely swallowable, effervescent, orodispersible and chewable, are currently available in the market.

Swallowable tablet is the most common oral tablet available in the market. It requires access to water to be swallowed in an intact dose form. Many multivitamin or multimineral tablets have to be swallowed whole due to the astringent and metallic taste contributed by a number of the active ingredients. Effervescent tablet is designed to dissolve in a liquid, normally water, resulting in a micronutrient drink with a short-term carbonation effect. The effervescent effect is produced by the reaction between bicarbonate and an acid, in the presence of water (Ottaway, 2008). Orodispersible tablet is designed to rapidly dissolve and disperse in the mouth in the presence of saliva before swallowing ( $\mathrm{Fu}$ et al., 2004). Chewable tablet is a tablet that is required to be broken up and chewed before ingestion. Chewable tablet is intended to disintegrate smoothly in the mouth, with or without actual chewing and it releases a pleasant taste leaving no bitter or unpleasant aftertaste. The effervescent, orodispersible and chewable tablets provide ease in drug administration and are given to those having difficulty in swallowing, especially children and the elderly. The effervescent, orodispersible and chewable tablets also provide better bioavailability of the active ingredients through by-passing the disintegration process (Varma, 2016).

At present, palm-based TRF supplements are available in the form of soft gel capsules. Swallowable, effervescent, orodispersible or chewable tablets carrying RDA or higher dosage of palm-based TRF are scarce on the market. Therefore, a study on the formulation and storage quality of palm-based TRF tablets is requisite. This short communication reports the stability of palm-based TRF in a chewable tablet formulation after one year storage at ambient temperature. The physical properties of the palm-based TRF chewable tablet are also reported. 


\section{MATERIALS AND METHODS}

\section{Materials}

Powdered palm-based TRF was purchased from Sime Darby Bioganic Sdn Bhd, Malaysia. Other ingredients for the chewable tablet were of food grade and obtained from Thoyyib Pharma (M) Sdn Bhd, Malaysia. Chemicals for TRF analysis were of high performance liquid chromatograhpy (HPLC) grade.

\section{Angle of Repose}

Thirty grams of chewable tablet pre-mix powder was passed through an $18 \mathrm{~mm}$ diameter aperture filter funnel to build a cone. The lower tip of the filter funnel was $10 \mathrm{~cm}$ from the ground. The distance between two edges of the powder cone was measured as diameter. The distance from the peak of the cone relative to its perpendicular surface was recorded as height. The angle of repose was calculated according to the following equation:

$$
\tan \theta=\frac{\text { height }}{\text { radius }}
$$

\section{Bulk Density}

Thirty grams of chewable tablet pre-mix powder was poured into a $100 \mathrm{ml}$ measuring cylinder. The volume of the powder was recorded. Bulk density was calculated according to the following equation:

$$
\text { Bulk density }=\frac{\text { weight }}{\text { volume }}
$$

\section{Tapped Density}

Thirty grams of chewable tablet pre-mix powder was poured into a $100 \mathrm{ml}$ measuring cylinder and tapped for 750 times with a fixed drop of $14 \pm 2 \mathrm{~mm}$ at a nominal rate of 300 drops per minute using a Tap Density Tester (Electrolab, India). The final volume was recorded. The tapped density was calculated according to the following equation:

$$
\text { Tapped density }=\frac{\text { weight }}{\text { final volume }}
$$

\section{Compressible Index}

Compressible index of chewable tablet pre-mix powder was calculated according to the following equation:

$$
\text { Compressible index }=\frac{(\text { Tapped density - bulk }}{\text { density) }} \times 100 \%
$$

\section{Hausner's Ratio}

Hausner's ratio of chewable tablet pre-mix powder was calculated according to the following equation:

$$
\text { Hausner's ratio }=\frac{\text { Tapped density }}{\text { Bulk density }}
$$

\section{Production of Chewable Tablet}

Chewable tablet pre-mix powder was prepared by thoroughly blending all the powdered ingredients followed by sieving using a 40-mesh sieve. The chewable tablet formulation carrying the palmbased TRF is shown in Table 1. The pre-mix was compressed into tablets of $1000 \mathrm{mg}$ each by a direct compression method, using an automatic tableting machine (Model EP200, Elizabeth Parle, India). The tablets were packed properly in screw-capped highdensity polyethylene bottles and kept for one-year at ambient temperature. Vitamin E content of the tablets was measured periodically (on Day 1, Day 30, Day 90, Day 180, Day 270 and Day 360). Other parameters, namely tablet hardness, friability and disintegration time were also measured.

\section{Vitamin E Content}

An amount of $0.01 \mathrm{~g}$ of ground chewable tablet sample was weighed. One millilitre of $0.9 \%$ sodium chloride, $1 \mathrm{ml}$ of ethanol and $5 \mathrm{ml}$ of $\mathrm{n}$-hexane were added to the sample. The mixture was shaken at 1000-1500 amplitude for $1 \mathrm{hr}$ and then centrifuged at $2500 \mathrm{rpm}$ for $10 \mathrm{~min}$. The supernatant was collected and blown dry with nitrogen gas. It was then diluted with a mobile phase consisting of $97.5 \mathrm{ml} \mathrm{n}$-hexane, $2 \mathrm{ml}$ 1,4-dioxine and $0.5 \mathrm{ml}$ 2-propanol. Vitamin E content was determined using HPLC with a Luna $5 \mu$ Silica 100A ODS (250 x 460 mm, $5 \mu \mathrm{m}$ particle size) Hypersil column (Phenomenex, USA). The column was maintained at a pressure of 28 bars and a temperature of $26^{\circ} \mathrm{C}$. Samples of $50 \mu \mathrm{l}$ volume were injected at a flow rate of $1 \mathrm{ml} \mathrm{min}^{-1}$ and a total

\section{TABLE 1. FORMULATION OF PALM-BASED TOCOTRIENOL-RICH FRACTION (TRF) CHEWABLE TABLET}

\begin{tabular}{lc}
\hline Ingredients & Percentage \\
\hline Powdered palm-based TRF containing & 10 \\
193.67 mg g-1 vitamin E & 10 \\
Vitamin C & 51.3 \\
Binder (carbohydrate, cellulosic material) & 7.5 \\
Compressible carbohydrate & 5.5 \\
Sweetener & 15.0 \\
Fruit juice powder (flavour) & 0.4 \\
Lubricant & 0.3 \\
Glidant & \\
\hline
\end{tabular}


run time of $30 \mathrm{~min}$. Vitamin E isomers were detected using a fluorescence detector at an excitation wavelength of $295 \mathrm{~nm}$ and an emission wavelength of $325 \mathrm{~nm}$. Individual chromatographic peaks were identified by comparing their peak elution time with those of vitamin E isomer standards and quantified using the peak area normalisation method.

\section{Tablet Hardness}

Hardness of tablets was measured using a tablet hardness tester with two test jaws (EZ Tab 400, Pharmag Instruments, India). The tablet was placed between the two jaws, one of which moves to apply sufficient force to the tablet to cause fracture. The force required to cause the tablet to break, expressed in kiloponds $(\mathrm{kp})$, is called the 'hardness' of the tablet.

\section{Tablet Friability}

Friability of tablets was tested using a friabilitor (PI-FTV-01, Pharmag Instruments, India) with a rotation speed of $25 \pm 1 \mathrm{rpm}$ for 100 cycles. Ten tablets were weighed and then placed in the friabilitor. After 100 cycles, the final weight was measured. Percentage friability was calculated by the following equation.

$$
\% \text { Friability }=\frac{\text { weight }_{\text {initial }} \text {-weight }_{\text {final }}}{\text { weight }_{\text {initial }}} \times 100
$$

\section{Tablet Disintegration Time}

Disintegration time of tablets was measured using a disintegration unit (DT1000, Pharmag Instruments, India). Six tablets were placed in a basket filled with water. The temperature of the water was set at $37^{\circ} \mathrm{C}$ to simulate human body temperature. The time taken for the tablets to dissolve completely was recorded as the disintegration time of tablets.

\section{Statistical Analysis}

Statistical analysis was conducted on triplicate measurements. Data were analysed with analysis of variance (ANOVA), using the Minitab 16 (Minitab Inc., State College, PA, USA) statistical software. Data were expressed as means with standard deviations. Statistical significance was determined using Tukey test at $p<0.05$.

\section{RESULTS AND DISCUSSION}

Palm-based TRF powder used in the chewable tablet formulation contained $193.67 \mathrm{mg} \mathrm{g}^{-1}$ vitamin E. The composition, and HPLC chromatogram of the palm-based TRF are shown in Table 2 and Figure 2, respectively. The palm-based TRF comprised about $77.74 \%$ tocotrienols $(\alpha-, \beta-, \gamma-$ and $\delta$-tocotrienol) and $22.26 \%$ tocopherol ( $\alpha$-tocopherol). The most abundant tocotrienols isomers in the palm-based TRF were $\gamma, \alpha$ and $\delta$ in descending order.

In formulating a chewable tablet, the flow properties of the powdered ingredients can greatly affect manufacturing efficiency and quality of the tablets. Hence, the flowability of the powdered ingredients is very critical. According to US Pharmacopeia (2006), powder flowability can be categorised into a few classes (Table $3 a$ ). The powder's flow properties were indicated by the angle of repose, compressible index and Hausner's ratio. Powders with poor flowability tend to form arches and ratholes in the hopper that restricts a continuous free flow mass from entering the tablet press machine and subsequently causes weight and content variation of the finished product due to the inconsistent amounts of powder flow during compression (Abhaykumar, 2006). The palmbased TRF chewable tablet powder pre-mix had a 'passable' flowability (Table 3b), indicating that it was possible to be compressed into tablets.

\section{Vitamin E Retention}

Retention of the vitamin $\mathrm{E}$ in the palm-based TRF chewable tablet after one-year storage at ambient temperature was excellent at $92.6 \%$, with the initial vitamin $\mathrm{E}$ content in the chewable tablet being $18.94 \mathrm{mg} \mathrm{g}^{-1}$, which undoubtedly due to the use of powdered/microencapsulated palmbased TRF in the chewable tablet formulation. Microencapsulation is a method in which microdroplets of bioactive components are surrounded by a coating to form microcapsules. Microencapsulation had been shown to protect bioactive components from direct exposure to chemical and physical

TABLE 2. CONTENTS OF TOCOTRIENOL AND TOCOPHEROL ISOMERS, AND TOTAL VITAMIN E IN POWDERED PALM-BASED TOCOTRIENOL-RICH FRACTION

\begin{tabular}{lc}
\hline Vitamin E isomers & Amount $\left(\mathbf{m g ~ g}^{-1}\right)$ \\
\hline Tocotrienol isomers & \\
$\alpha$-tocotrienol & $55.75 \pm 0.09$ \\
$\beta$ - tocotrienol & $4.52 \pm 0.01$ \\
$\gamma$-tocotrienol & $58.79 \pm 0.10$ \\
$\delta$-tocotrienol & $31.41 \pm 0.02$ \\
Tocopherol isomers & \\
$\alpha$-tocopherol & $43.19 \pm 0.34$ \\
$\beta$-tocopherol & n.d \\
$\gamma$-tocopherol & n.d \\
$\delta$-tocopherol & n.d \\
Total vitamin E (tocopherol + tocotrienol) & $193.67 \pm 0.53$ \\
\hline
\end{tabular}

Note: n.d. - not detected. 


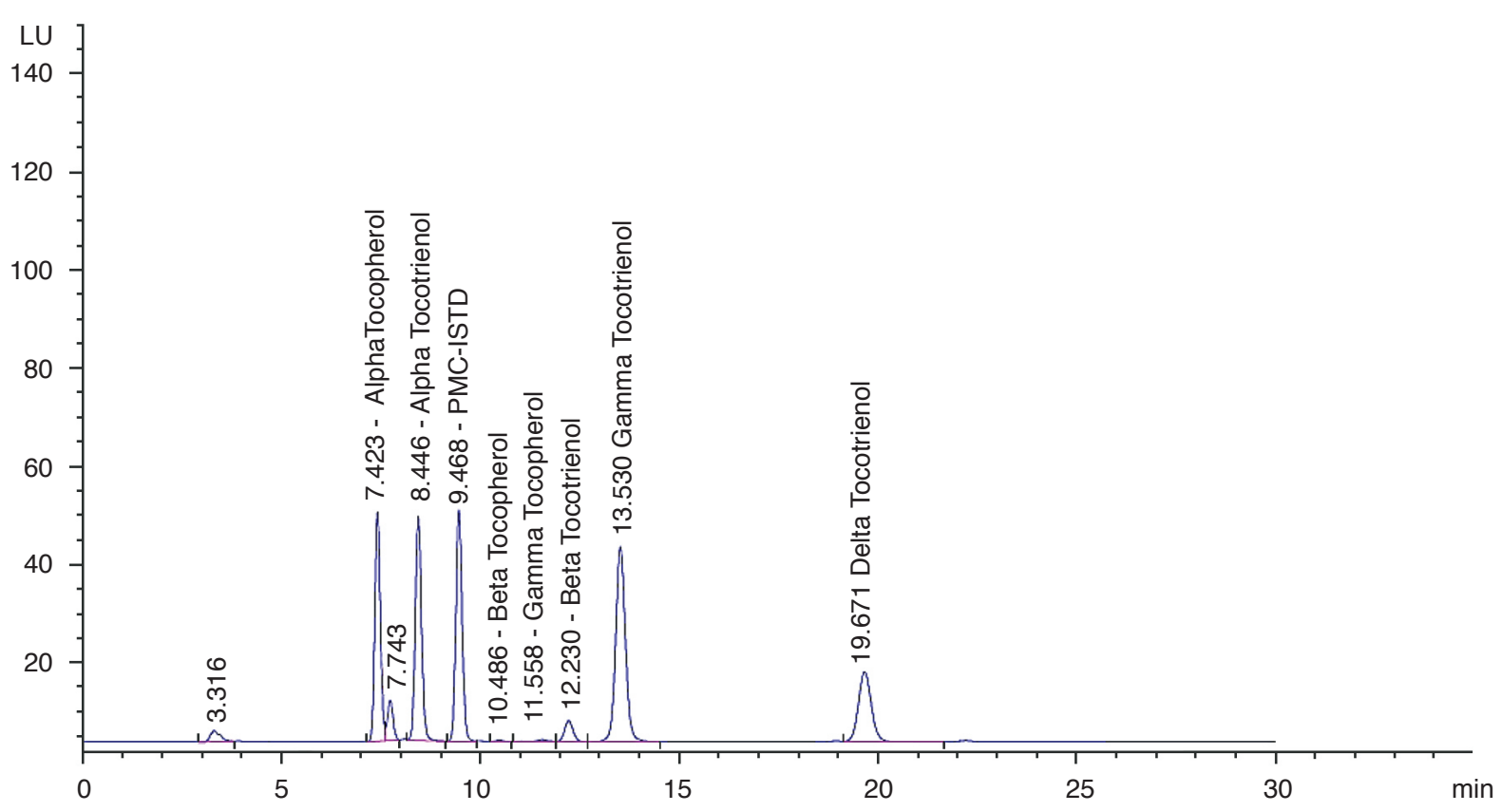

Figure 2. High performance liquid chromatography (HPLC) chromatogram of powdered palm-based tocotrienol-rich fraction.

TABLE 3. THE SCALE OF POWDER FLOWABILITY ACCORDING TO US PHARMACOPEIA AND FLOW PROPERTIES OF PALM-BASED TOCOTRIENOL-RICH FRACTION CHEWABLE TABLET PRE-MIX

\begin{tabular}{lccc}
\hline & a. THE SCALE OF POWDER FLOWABILITY ACCORDING TO US PHARMACOPEIA & A \\
\hline Flowability & Angle of repose $\left(^{\circ}\right)$ & Compressible index (\%) & Hausner's ratio \\
\hline Excellent & $25-30$ & $\leq 10$ & $1.00-1.11$ \\
Good & $31-35$ & $11-15$ & $1.12-1.18$ \\
Fair - aid not needed & $36-40$ & $16-20$ & $1.19-1.25$ \\
Passable - may hang up & $41-45$ & $21-25$ & $1.26-1.34$ \\
Poor - must agitate or vibrate & $46-55$ & $26-31$ & $1.35-1.45$ \\
Very poor & $56-65$ & $32-37$ & $1.46-1.59$ \\
Very, very poor & $>66$ & $>38$ & $>1.6$ \\
\hline
\end{tabular}

b. FLOW PROPERTIES OF PALM-BASED TOCOTRIENOL-RICH FRACTION CHEWABLE TABLET PRE-MIX

\begin{tabular}{lccc}
\hline Flowability & Angle of repose $\left({ }^{\circ}\right)$ & Compressible index (\%) & Hausner's ratio \\
\hline Passable & $19.09 \pm 0.4$ & 22.88 & 1.30 \\
\hline
\end{tabular}

reactions, thus protecting the bioactive ingredients from degradation (Calvo et al., 2011). Vitamin E retention in two commercial tablets containing 70.6 and $153.8 \mathrm{mg} \mathrm{g}^{-1}$ vitamin $\mathrm{E}$ (as indicated on the labels), was also determined right after purchase from a local pharmacy store. A 100\% loss of vitamin E was observed in both commercial vitamin E-containing tablets (Figure 3). Vitamin E deterioration during storage might be due to some extrinsic factors such as heat, light or air that might have caused oxidation of the vitamin (Schauss et al., 2012).

\section{Tablet Hardness, Friability and Disintegration} Time

The hardness of chewable tablets should be such that they can withstand the rigors of manufacturing, packaging, shipping and distribution as well as be easily chewed by the intended consumers. It is recommended that hardness of chewable tablets be kept low (i.e. $<12 \mathrm{kp}$ ), so that the tablets can be safely chewed without damaging teeth or dentures, or cause other adverse effects associated with chewing these tablets (US Pharmacopeia, 2015). Commercial chewable tablets have a hardness value ranging from 2-11 kp (Robinson et al., 2001). Friability is closely related to tablet hardness and is designed to evaluate the tendency of the tablet to chip, crumble or break upon exposure to mechanical shock and attrition during packaging, handling and shipping. Friability should be $<1 \%$. Chewable tablets need to be hard enough so that they do not break up in the bottle but are friable enough so that they are chewable and will disintegrate in the gastrointestinal 
(a)

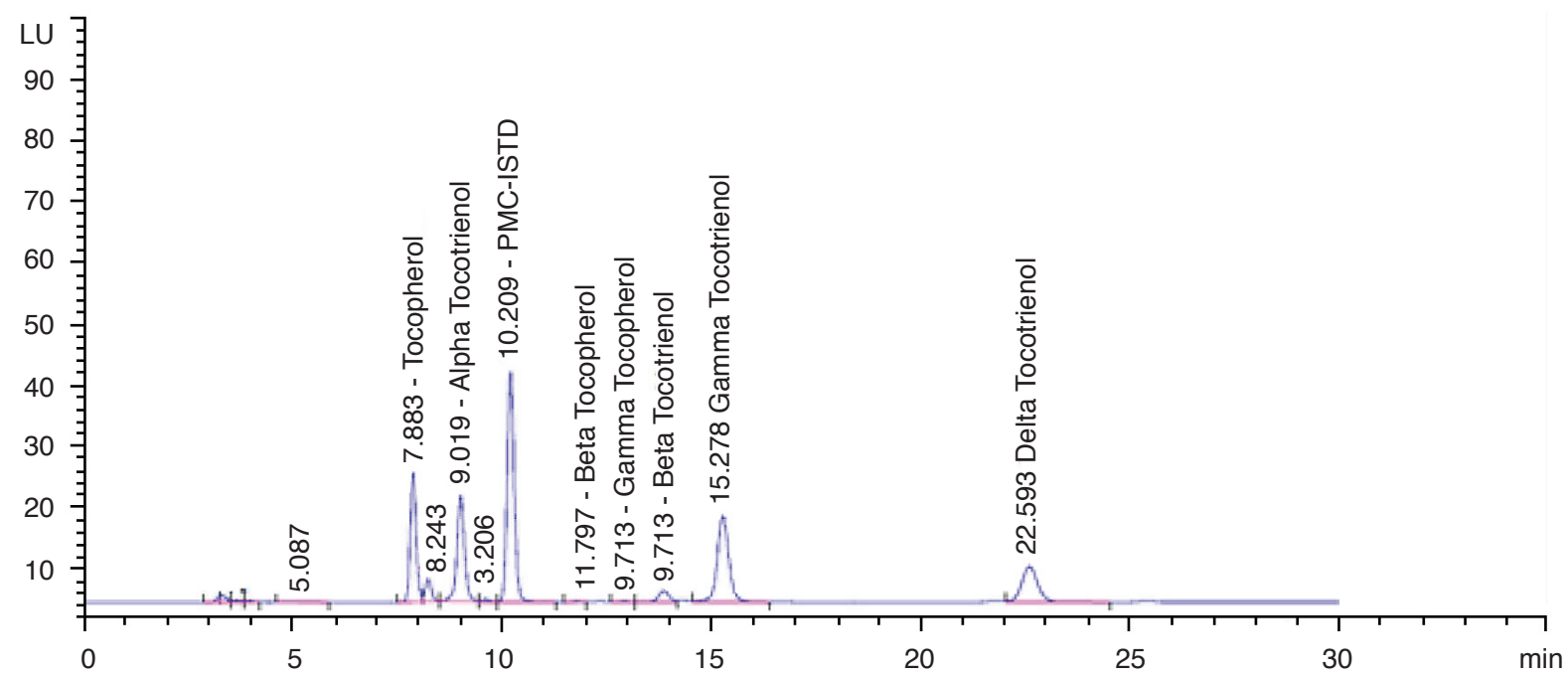

(b)

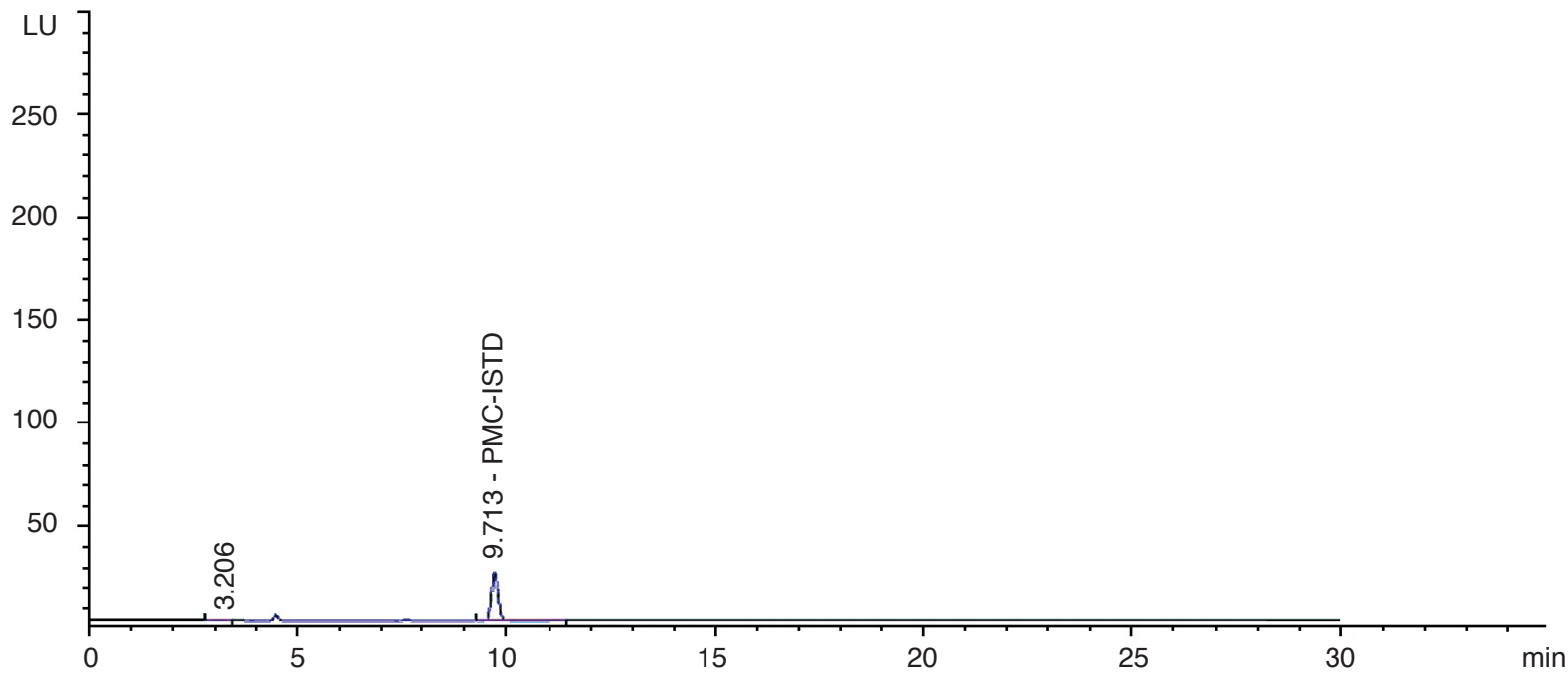

(c)

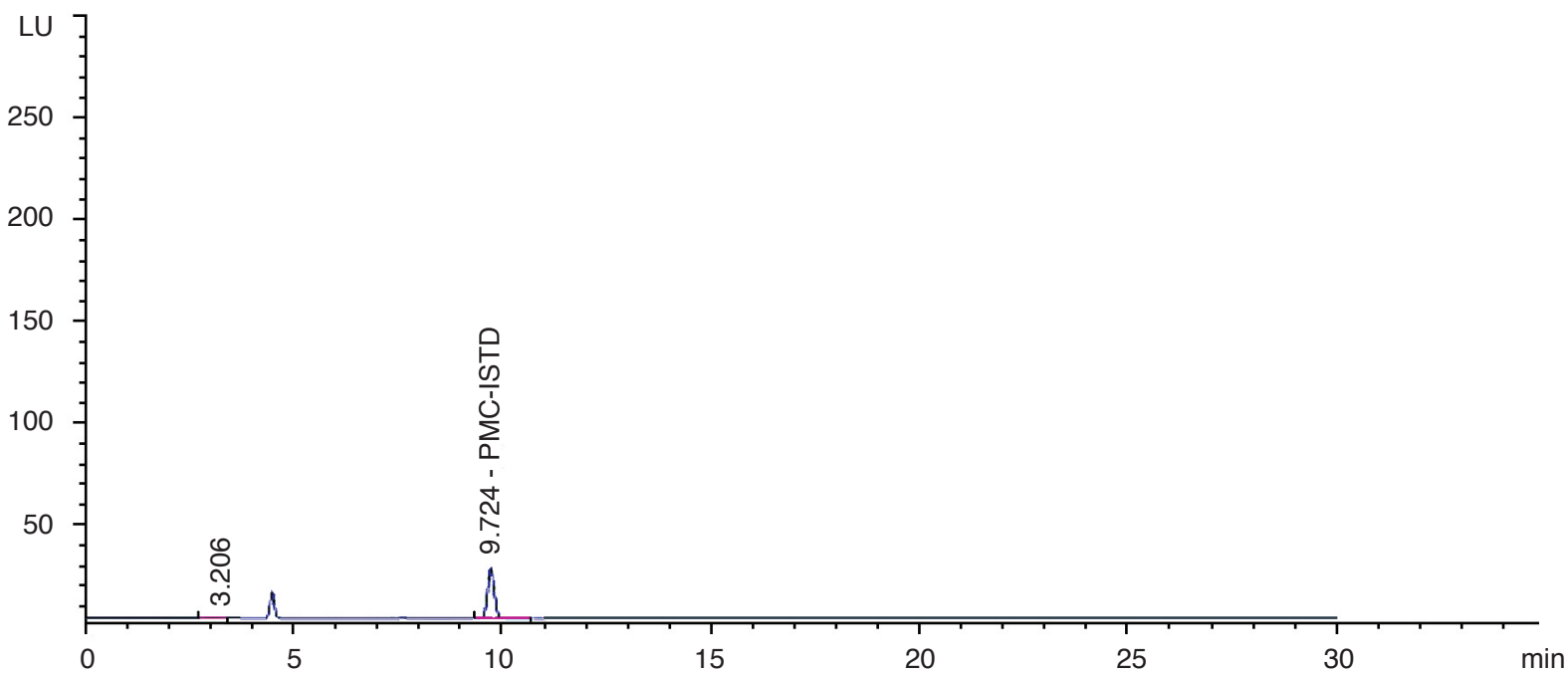

Figure 3. High performance liquid chromatography (HPLC) chromatogram showing vitamin E isomers of palm-based tocotrienol-rich fraction chewable tablet (a) (after 12 months storage at ambient temperature), (b) and (c) commercial tablets containing vitamin E purchased from pharmacy store that was manufactured (as stated on the labels) 10 and 14 months prior to analysis, respectively. 
TABLE 4. VITAMIN E CONTENT OF PALM-BASED TOCOTRIENOL-RICH FRACTION CHEWABLE TABLET UPON ONE-YEAR OF STORAGE AT AMBIENT TEMPERATURE

\begin{tabular}{|c|c|c|c|c|c|c|}
\hline \multirow{2}{*}{ Vitamin E } & \multicolumn{6}{|c|}{ Vitamin $E$ content $\left(\mathrm{mg} \mathrm{g}^{-1}\right)$} \\
\hline & Day 1 & Day 30 & Day 90 & Day 180 & Day 270 & Day 360 \\
\hline \multicolumn{7}{|c|}{ Tocotrienol isomers } \\
\hline$\alpha$-tocotrienol & $5.51 \pm 0.04^{\mathrm{a}}$ & $5.38 \pm 0.03^{b}$ & $5.31 \pm 0.03^{b c}$ & $5.25 \pm 0.02^{c}$ & $5.16 \pm 0.07^{d}$ & $5.03 \pm 0.03^{e}$ \\
\hline$\beta$ - tocotrienol & $0.39 \pm 0.04^{\mathrm{a}}$ & $0.40 \pm 0.01^{\mathrm{a}}$ & $0.41 \pm 0.01^{\mathrm{a}}$ & $0.38 \pm 0.01^{\mathrm{a}}$ & $0.39 \pm 0.01^{\mathrm{a}}$ & $0.39 \pm 0.01^{\mathrm{a}}$ \\
\hline$\gamma$-tocotrienol & $5.38 \pm 0.09^{a}$ & $5.35 \pm 0.02^{\mathrm{a}}$ & $5.29 \pm 0.02^{\mathrm{ab}}$ & $5.21 \pm 0.12^{b}$ & $5.13 \pm 0.02^{c}$ & $4.89 \pm 0.01^{\mathrm{d}}$ \\
\hline$\delta$-tocotrienol & $2.98 \pm 0.01^{\mathrm{a}}$ & $2.99 \pm 0.02^{\mathrm{a}}$ & $2.98 \pm 0.02^{\mathrm{a}}$ & $2.98 \pm 0.01^{\mathrm{a}}$ & $2.96 \pm 0.3^{\mathrm{a}}$ & $3.02 \pm 0.10^{\mathrm{a}}$ \\
\hline \multicolumn{7}{|c|}{ Tocopherol isomers } \\
\hline$\alpha$-tocopherol & $4.68 \pm 0.01^{\mathrm{a}}$ & $4.50 \pm 0.02^{\mathrm{b}}$ & $4.46 \pm 0.02^{\mathrm{bc}}$ & $4.42 \pm 0.02^{c}$ & $4.33 \pm 0.03^{\mathrm{d}}$ & $4.21 \pm 0.01^{\mathrm{e}}$ \\
\hline$\beta$-tocopherol & n.d & n.d & n.d & n.d & n.d & n.d \\
\hline$\gamma$-tocopherol & n.d & n.d & n.d & n.d & n.d & n.d \\
\hline$\delta$-tocopherol & n.d & n.d & n.d & n.d & n.d & n.d \\
\hline $\begin{array}{l}\text { Total vitamin E } \\
\text { (tocotrienols }+ \\
\text { tocopherols) }\end{array}$ & $18.94 \pm 0.09^{a}$ & $18.62 \pm 0.11^{\mathrm{b}}$ & $18.45 \pm 0.08^{\mathrm{bc}}$ & $18.24 \pm 0.15^{c}$ & $17.97 \pm 0.14^{\mathrm{c}}$ & $17.54 \pm 0.17^{\mathrm{d}}$ \\
\hline
\end{tabular}

Note: Means within each row bearing different superscript letters are significantly different $(p<0.05)$. n.d - not detected.

tract (Saleem et al., 2014). The hardness and friability of the palm-based TRF chewable tablet were within the acceptable ranges, i.e., $5.64 \mathrm{kp}$ and $0.12 \%$, respectively. Disintegration time is the time required for a tablet to break up into small particles of specified size under carefully specified conditions. In this study, the disintegration time of the chewable tablets referred to the time required for the tablet to fully dissolve at $37^{\circ} \mathrm{C}$, i.e., human body temperature (in the event that the chewable tablet is being 'sucked' instead of being chewed in the oral cavity). The disintegration time of the palm-based TRF chewable tablet (27 $\mathrm{min}$ ) was comparable to that of commercial chewable tablets (ranging from 25-32 $\mathrm{min})$. There were slight increases in hardness $(7.79 \mathrm{kp})$ and disintegration time (approximately $31 \mathrm{~min}$ ) after 360 days of storage but these values were still within the acceptable ranges. There was no significant change in friability after one-year of storage.

\section{CONCLUSION}

Palm-based vitamin E had excellent stability in chewable tablet formulated using $10 \%$ powdered palm-based TRF (which contains $193.67 \mathrm{mg} \mathrm{g}^{-1}$ vitamin E) after one-year of storage at ambient temperature. After that period of storage, retention of the total vitamin $\mathrm{E}$ was $92.6 \%$, with the initial vitamin $\mathrm{E}$ content in the chewable tablet being $18.94 \mathrm{mg} \mathrm{g}^{-1}$. By comparison, two commercial tablets containing 70.6 and $153.8 \mathrm{mg} \mathrm{g}^{-1}$ vitamin E (as indicated on the labels) showed 100\% loss after 10 and 14 months from the date of manufacture, respectively.

\section{ACKNOWLEDGEMENT}

This work was supported by MPOB. The authors acknowledge the Director-General of MPOB for permission to publish this article. The authors also acknowledge Ghazali Abd Razak, Muhamad Adrina Malek and Isham Ismail of MPOB for their contribution in ensuring the success of this study.

\section{REFERENCES}

Abhaykumar, B (2006). Correlation between Physical Properties and Flowability Indicators for Fine Powders. A thesis of Master of Science, Department of Chemical Engineering, University of Saskatchewan, Saskatoon. 122 pp.

Brigelius-Flohé, R and Traber, M G (1999). Vitamin E: Function and metabolism. The FASEB J., 13: 11451155.

Calvo, P; Castano, A L; Hernandez, M T and GonzalezGomez, D (2011). Effects of microcapsule constitution on the quality of microencapsulated walnut oil. European J. Lipid Science and Technology, 113: 1273-1280.

Cerecetto, H and Lopez, G V (2007). Antioxidants derived from vitamin E: An overview. Mini Reviews in Medicinal Chemistry, 7: 315-338.

Fu, Y; Yang, S; Jeong, S H; Kimura, S and Park, K (2004). Orally fast disintegrating tablets: Developments, technologies, taste-masking and clinical studies. Critical Reviews ${ }^{\mathrm{TM}}$ in Therapeutic Drug Carrier Systems, 21: 433-476. 
Heng, E; Karsani, S; Abdul Rahman, M; Abdul Hamid, N; Hamid, Z and Wan Ngah, W Z (2013). Supplementation with tocotrienol-rich fraction alters the plasma levels of apolipoprotein a-I precursor, apolipoprotein E precursor and C-reactive protein precursor from young and old individuals. European J. Nutrition, 52: 1811-1820.

Kushairi, A; Loh, S K; Azman, I; Hishamuddin, E; Ong-Abdullah, M; Izuddin, Z B M N; Razmah, G; Sundram, S and Parveez, G K A (2018). Oil palm economic performance in Malaysia and R\&D progress in 2017. J. Oil Palm Res. Vol. 30(2): 163-195.

Ottaway, P B (2008). Food Fortification and Supplementation: Technological, Safety and Regulatory Aspects. Woodhead Publishing Ltd, Cambridge, UK. 296 pp.

Pharmacopeia, U S (2006). Bulk Density and Tapped Density. Rockville, USP. 3 pp.

Pharmacopeia, U S (2015). Tablet Breaking Force. Rockville, USP. 3 pp.

Puah, C W; Choo, Y M; Ma, A N and Chuah, C H (2007). The effect of physical refining on palm vitamin E (tocopherol, tocotrienol and tocomonoenol). American J. Applied Sciences, 4: 374-377.

Qureshi, A A; Bradlow, B A; Brace, L; Manganello, J; Peterson, D M; Pearce, B C; Wright, J J; Gapor, A and Elson, C E (1995). Response of hypercholesterolemic subjects to administration of tocotrienols. Lipids, 30: 1171-1177.
Robinson, R L; Damon, J R; Mossop, J R and Palmer, M D (2001). Soft, convex shaped chewable tablets having reduced friability. US patent No. 6,270,790. Washington, DC: US Patent and Trademark Office.

Saleem, M; Shahin, M; Srinivas, B and Begum, A (2014). Evaluation of evaluation of tablets by friability apparatus. International J. Research in Pharmacy and Chemistry, 4: 837-840.

Schauss, A G; Endres, J R and Clewell, A (2012). Safety of unsaturated vitamin $\mathrm{E}$ tocotrienols and their isomers. Tocotrienols: Vitamin E Beyond Tocopherols (Tan, B; Watson, R R and Preedy, V R eds.). AOCS Press. Urbana IL, USA. p. 17-35.

Sen, C K; Khanna, S; Roy, S and Packer, L (2000). Molecular basis of vitamin E action tocotrienol potently inhibits glutamate-induced (c-Src) kinase activation and death of HT4 neuronal cells. J. Biological Chemistry, 275: 13049-13055.

Tan, D T; Khor, H T; Low, W H; Ali A and Gapor, A (1991). Effect of a palm-oil-vitamin E concentrate on the serum and lipoprotein lipids in humans. The American J. Clinical Nutrition, 53: 1027S-1030S.

Traber, M G (2014). Vitamin E inadequacy in humans: Causes and consequences. Advanced Nutrition, 5: 503-514.

Varma, K (2016). Excipients used in the formulation of tablets. Research and Reviews: J. Chemistry, 5: 143-155.

Wong, R S Y and Radhakrishnan, A K (2012). Tocotrienol research: Past into present. Nutrition Reviews, 70: 483-490. 